Bull. Mater. Sci., Vol. 36, No. 4, August 2013, pp. 667-672. (C) Indian Academy of Sciences.

\title{
Combustion synthesis of graphene and ultracapacitor performance
}

\author{
M SATYA KISHORE, P SRIMATHI, SUNDEEP KUMAR*, SWARNAGOWRI ADDEPALLI, \\ SRINIVASAN SWAMINATHAN, VINAYAK TILAK and ROBERT COLBORN ${ }^{\dagger}$ \\ GE Global Research, John F Welch Technology Centre, Bangalore 560 066, India \\ ${ }^{\dagger}$ GE Global Research, 1 Research Circle, Niskayuna, NY 12309, USA
}

MS received 28 December 2011; revised 28 September 2012

\begin{abstract}
Graphene sheets are synthesized by a simple method starting from graphitic oxide as a precursor. Reaction of graphitic oxide at $250{ }^{\circ} \mathrm{C}$ with a combustion mixture of urea and ammonium nitrate results in the formation of thin graphene sheets. Graphene formation is characterized by XRD, TGA, XPS and TEM. Graphene materials synthesized by this method are investigated as an ultracapacitor material. Specific capacitance values of about $70 \mathrm{~F} / \mathrm{g}$ are obtained at a current density of $100 \mathrm{~mA} / \mathrm{g}$ by using $\mathrm{KOH}$ as an electrolyte.
\end{abstract}

Keywords. Combustion synthesis; graphene; ultracapacitor performance.

\section{Introduction}

A flat monolayer of carbon atoms bonded together in a hexagonal lattice is called 'graphene' (Geim and Novoselov 2007; Geim 2009). Graphene possesses remarkably high values of Young's modulus (1100 GPa) (Lee et al 2008), fracture strength (125 GPa) (Lee et al 2008), thermal conductivity $\left(\sim 5000 \mathrm{Wm}^{-1} \mathrm{~K}^{-1}\right.$ ) (Balandin et al 2008), mobility of charge carriers $\left(200,000 \mathrm{~cm}^{2} \mathrm{~V}^{-1} \mathrm{~s}^{-1}\right)$ (Bolotin et al 2008) and specific surface area (calculated value of $2630 \mathrm{~m}^{2} / \mathrm{g}$ ) (Stroller et al 2008). In ultracapacitor, energy is stored at the electrode/electrolyte interface by charge separation of electrolyte ions. Energy can be enhanced by increasing the accessible surface area for electrolyte ions on the electrode surface. The extremely high surface area of graphene offers promise for its use as an ultracapacitor.

Graphene has been made by several synthesis routes. The original method to make graphene is by micromechanical exfoliation, which is also referred to sometimes as 'scotch tape' or 'peel-off method' (Novoselov et al 2004). Graphene has often been made by chemical vapour deposition (CVD) technique, by which graphene films can be made on different metal substrates (Somani et al 2006). However, for ultracapacitor application graphene in powder form is preferred and hence, alternative chemical routes are required through which bulk quantities of graphene can be prepared. Park and Ruoff (2009) summarized different chemical routes reported in the literature to make graphene through colloidal suspension routes (Park and Ruoff 2009). Graphene synthesized by chemical route is primarily obtained through reduction of graphitic oxide (GO), latter being synthesized based on procedures of Brodie (1860), Staudenmaier (1898) and Hummers and Offeman (1958). In all these three methods,

\footnotetext{
*Author for correspondence (sundeep.kumar1@ge.com)
}

graphite is treated with strong acids and oxidants. Although the detailed molecular structure of graphitic oxide is not determined, it has been suggested to have a chemical structure such that the $s p^{2}$ bonded carbon network of graphite is disrupted through bonding to hydroxyl and epoxide groups (He et al 1996; Lerf et al 1998). The edges of the layers in graphitic oxide may also contain carboxylic or carbonyl groups. Ajayan's group (Gao et al 2009) have recently shown the presence of five- and six-membered ring lactols. Functional groups from $\mathrm{GO}$ have been removed by using reducing agents such as hydrazinehydrate (Stroller et al 2008), hydroquinone (Wang et al 2008) and $\mathrm{NaBH}_{4}$ (Muszynski et al 2008) to obtain graphene.

Ultracapacitor performance of graphene is highly dependent on its synthesis method, electronic conductivity, accessible surface area and electrolyte ions (Singh et al 2011). Generally, aqueous-based electrolyte $\mathrm{KOH}$ is being used to characterize ultracapacitor electrode material. Depending on the synthesis route, graphene exhibits specific capacitance in the range of 60-200 F/g for $\mathrm{KOH}$ electrolyte (Stroller et al 2008; Wang et al 2009; Zhu et al 2010a; Du et al 2010a). Colloidal suspension of graphitic oxide in water is chemically reduced using hydrazine hydrate at $90{ }^{\circ} \mathrm{C}$ to produce graphene with a specific capacitance of $\sim 130 \mathrm{~F} / \mathrm{g}$ (Stroller et al 2008). In contrast, graphene synthesized by gas-based reduction of graphitic oxide using hydrazine hydrate as a reducing agent, gives rise to ultracapacitor performance of $200 \mathrm{~F} / \mathrm{g}$ (Wang et al 2009). Graphene synthesized by irradiating graphitic oxide to microwave radiation (Zhu et al 2010a) also demonstrated specific capacitance of $\sim 200 \mathrm{~F} / \mathrm{g}$. Graphene nanosheets were produced by rapid heating process of graphitic oxide and ultracapacitor performance of 60-120 F/g was demonstrated depending upon heat treatment (Du et al 2010a).

New synthesis routes for graphene still remain a field of immense research activity with focus on inexpensive and 
scalable methods to produce graphene. In this study, we report a new 'combustion method' to synthesize graphene and its ultracapacitor performance.

\section{Experimental}

\subsection{Synthesis of graphitic oxide}

Graphitic oxide was synthesized from graphite powder (Sigma Aldrich, $<20 \mu \mathrm{m}$ ) using modified Hummer and Offman's (1958) method. In a typical synthesis, $2 \mathrm{~g}$ of graphite was taken into $1 \mathrm{~L}$ round-bottomed flask. The flask was then kept in an ice bath and $50 \mathrm{~mL}$ of concentrated sulfuric acid was added to it. Then, $7 \mathrm{~g}$ of $\mathrm{KMnO}_{4}$ was slowly added to the mixture. Care was taken to ensure that temperature does not increase beyond $10{ }^{\circ} \mathrm{C}$ during the addition of $\mathrm{KMnO}_{4}$. This solution was stirred for $4 \mathrm{~h}$, followed by heating at $35^{\circ} \mathrm{C}$ for $2 \mathrm{~h}$. To this mixture, $100 \mathrm{~mL}$ of deionized (DI) water was added slowly. The addition of water to conc. $\mathrm{H}_{2} \mathrm{SO}_{4}$ released large amount of heat, hence, addition of water was performed in an ice bath to ensure that the solution temperature was below $50^{\circ} \mathrm{C}$. The resultant solution was further diluted to $200 \mathrm{~mL}$ by adding DI water and stirred for $2 \mathrm{~h}$. After that, $10 \mathrm{~mL}$ of $30 \% \mathrm{H}_{2} \mathrm{O}_{2}$ was added drop wise to this solution, which resulted in dark yellow-coloured solution. Finally, the mixture was washed thoroughly with 5\% $\mathrm{HCl}$ and centrifuged. The product was washed with DI water for several times to remove the residual salts and acid. The resulting solid was dried at $60{ }^{\circ} \mathrm{C}$ in a vacuum oven for $12 \mathrm{~h}$.

\subsection{Synthesis of graphene}

For combustion synthesis, urea was used as fuel and ammonium nitrate as an oxidizer (Biamino and Badini 2004; Bhatkar et al 2007). Typical synthesis involved dispersion of $100 \mathrm{mg}$ of $\mathrm{GO}$ in $50 \mathrm{~mL}$ of DI water with ultrasonication for $30 \mathrm{~min}$. A second solution was prepared with $0.9 \mathrm{~g}$ of urea and $1.2 \mathrm{~g}$ of ammonium nitrate dissolved in $5 \mathrm{~mL}$ of DI water. This solution was added to GO dispersion. The combined solution was stirred and heated to $150{ }^{\circ} \mathrm{C}$, resulting in a thick colloidal suspension. This colloidal solution was then heated to $250{ }^{\circ} \mathrm{C}$ for $2 \mathrm{~h}$ in air on a hot plate. The thermal treatment resulted in evolution of vapours leaving a black powder product. The product was washed several times with DI water, followed by washing with methanol and dried at $60{ }^{\circ} \mathrm{C}$ (com-graphene). For comparison, GO suspension in $\mathrm{H}_{2} \mathrm{O}$ was heated to $250{ }^{\circ} \mathrm{C}$ for $2 \mathrm{~h}$ without fuel, hereafter referred to as T250-graphene.

\subsection{Characterization}

Graphene was characterized by X-ray diffraction (XRD), $\mathrm{X}$-ray photoelectron spectroscopy (XPS) and thermogravimetric analysis (TGA). XRD measurements were performed using Panalytical X-ray diffractometer with $\mathrm{CuK} \alpha$ radiation.

Surface analyses of the as-received samples by XPS were conducted in an Omicron Nanotechnology ESCAPROBE
MK II ultrahigh vacuum (UHV) surface analysis system with a base pressure of $\leq 1 \times 10^{-10} \mathrm{mbar}$ after bake-out. XPS spectra were acquired using $\operatorname{MgK} \alpha$ achromatic X-ray source $(h v=1253.6 \mathrm{eV})$ operated at $300 \mathrm{~W}$, a SPHERA ${ }^{\circledR}$ electrostatic energy analyser operated in the constant analyser energy (CAE) mode (pass energy fixed at $5 \mathrm{eV}$ ) and a 7-channel detector. Photoelectron spectra were corrected for surface charging against the $\mathrm{C}-\mathrm{C} / \mathrm{C}-\mathrm{H}$ bond $(\sim 284.6 \mathrm{eV})$. Binding energy values from photoelectron spectra were compared against literature values and standard reference data for chemical environment identification.

TGA/DSC measurements of GO and GO-combustion mixtures were carried out in air at $5{ }^{\circ} \mathrm{C} / \mathrm{min}$ (SetaramLabsys $16 / 18$ ). Morphology of the powders were investigated using scanning electron microscopy (SEM) and transmission electron microscopy (TEM). SEM images were acquired in secondary electron imaging (SEI) mode using JEOL 6335-F field emission scanning electron microscope (FESEM). TEM analysis was performed using JEOL 2010 instrument operating with $\mathrm{LaB}_{6}$ filament at $200 \mathrm{kV}$. The samples for TEM analysis were prepared by diluting the graphene in methanol followed by ultrasonication. Few drops of the ultrasonicated liquid containing graphene were placed onto holey carbon grids, dried and examined under TEM.

The ultracapacitor test cells were assembled by using Swagelok two-electrode cell. Electrodes were fabricated by mixing $95 \mathrm{wt} \%$ of graphene with $5 \mathrm{wt} \%$ PVDF binder in $N$-methyl pyrolidone (NMP). The paste was applied on nickel mesh, which was dried in an oven at $90{ }^{\circ} \mathrm{C}$ for $1 \mathrm{~h}$. The dried electrodes were separated with Celgard 3501 membrane and $1 \mathrm{M} \mathrm{KOH}$ was used as an electrolyte. Cyclic voltammetry $(\mathrm{CV})$ and galvanostatic charge-discharge of the cells were measured using Solartron 1480 potentiostat. CV measurements were done at different scanning rates varying from 2 to $25 \mathrm{mV} / \mathrm{s}$. Galvanostatic charge-discharge measurements were performed between 0 and $1.0 \mathrm{~V}$ at different current densities.

\section{Results and discussion}

The oxidation product of graphite gives graphitic oxide (GO), wherein the graphite layers are separated by several functional groups including hydroxyl, epoxy and carboxyl moieties. XRD pattern of GO is shown in figure 1. For comparison, XRD pattern of graphite is given, which has a main peak at $\sim 26^{\circ}$ corresponding to $\left(\begin{array}{lll}0 & 0 & 2\end{array}\right)$ reflection (figure 1 ). This peak is absent in GO indicating that graphite is oxidized completely. Further in GO, main peak is observed at $\sim 10^{\circ}$, which is in agreement with earlier reports ( Du et al 2010b). XRD pattern of com-graphene shows broad (ll 0 l 2 ) diffraction peak at $\sim 26^{\circ}$ and peak from starting phase is absent, suggesting that the functional groups are removed from GO. It is known that graphene nanosheets are formed by thermal treatment of GO at high temperatures (Du et al 2010a). In order to investigate the effect of thermal treatment, graphitic oxide suspension in $\mathrm{H}_{2} \mathrm{O}$ alone was heated at 


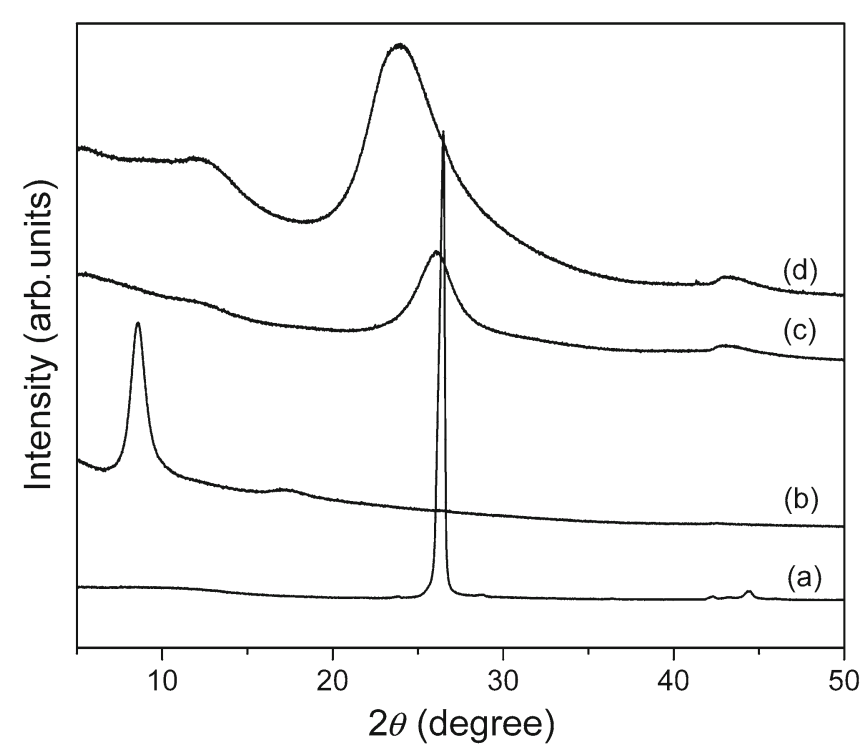

Figure 1. XRD pattern of (a) graphite, (b) graphitic oxide, (c) com-graphene and (d) T250-graphene.

$250{ }^{\circ} \mathrm{C}$ for $2 \mathrm{~h}$. XRD of T250-graphene shows a peak centred around $23^{\circ}$ with a shoulder at $\sim 25^{\circ}$ (figure 1). The $d$-spacing value for T250-graphene is $3.723 \AA$, which is higher than com-graphene, $3 \cdot 370 \AA$ A. It indicates that the spacing between layers is high for T250-graphene, in other words, it has significant amounts of functional groups lying between the layers compared to com-graphene. Further, this confirms that combustion mixture had generated high thermal energy locally which lead to the removal of functional groups from GO. The thickness for com-graphene sample is calculated from XRD data by using Debye-Scherrer equation, $t=$ $0.9 \lambda / \beta \cos \theta$, wherein $\beta=$ FWHM for $\left(\begin{array}{ll}0 & 0\end{array}\right)$ reflection and $\lambda=$ wavelength. The crystalline thickness is estimated to be $\sim 35 \mathrm{~nm}$, corresponding to $\sim 10$ layers $\left(t / d_{002}\right)$.

In order to understand the mechanism of combustion reaction carried out in this study, a series of thermal experiments are carried out on GO and GO-combustion mixture. Figure 2(a) shows TGA and figure 2(b) shows DSC scans for these samples. GO exhibits two steps in TGA: first is a gradual weight loss of about $20 \%$ starting at $50{ }^{\circ} \mathrm{C}$ until $150{ }^{\circ} \mathrm{C}$ and second is a sharp weight loss of about $72 \%$ at $150^{\circ} \mathrm{C}$. Overall weight loss for graphitic oxide is about $92 \%$, which agrees well with reported values (Wakeland et al 2010; Zhu et al 2010b). The first step of about $20 \mathrm{wt} \%$ loss may be associated to the loss of water from GO. The second step of $\sim 72 \mathrm{wt} \%$ loss is associated with the loss of epoxy oxygen and hydroxyl group from GO. In literature, TGA of urea has been reported; it shows two distinct steps of weight losses, first at $\sim 250{ }^{\circ} \mathrm{C}$ and second at $\sim 500{ }^{\circ} \mathrm{C}$ (Biamino and Badini 2004). GOcombustion mixture shows a different TGA profile compared to that of urea and graphitic oxide. First step of $\sim 5 \mathrm{wt} \%$ belongs to loss of water from the mixture and second step around $230^{\circ} \mathrm{C}$ is associated with about $85 \%$ weight loss. This second step around $230^{\circ} \mathrm{C}$ is the one, which is observed only
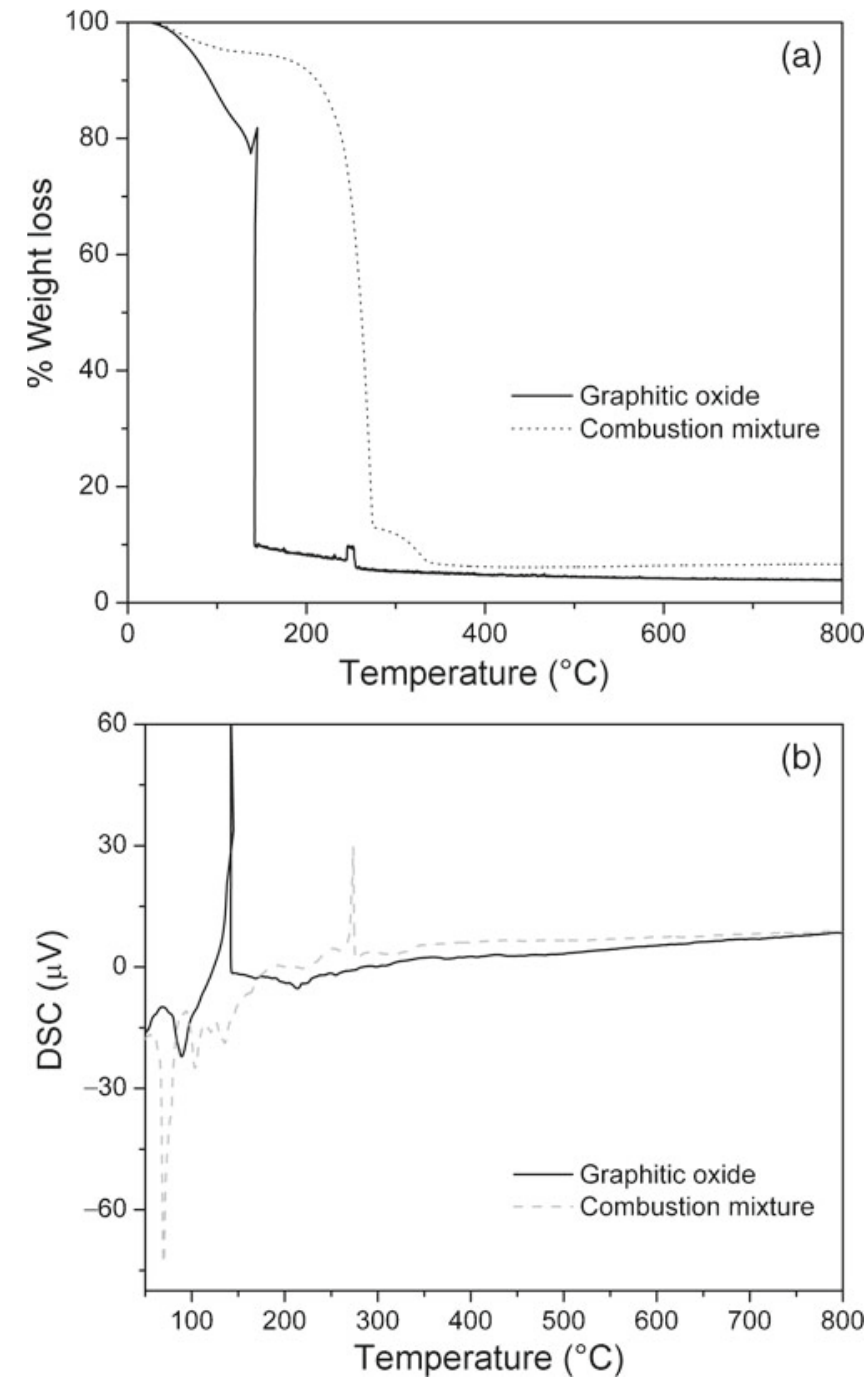

Figure 2. TGA/DSC data of graphitic oxide and combustion mixture. Experiments were conducted at a scanning rate of $5^{\circ} \mathrm{C} / \mathrm{min}$ in air.

in the case of combustion mixture. In DSC, this is reflected as an exothermal peak. This unique feature is due to the reaction of ammonium nitrate and urea (Biamino and Badini 2004). The heat generated at this step would result in rapid thermal expansion of GO. This feature is observed as endothermic in the case of reaction of graphitic oxide with urea alone at $\sim 250^{\circ} \mathrm{C}$ (Wakeland et al 2010). Further, it was reported that $600{ }^{\circ} \mathrm{C}$ is necessary to react GO powder with urea (Wakeland et al 2010). However, in our work, the synthesis temperature is decreased to $250^{\circ} \mathrm{C}$ with the aid of ammonium nitrate.

Figure 3 shows SEM and TEM images of com-graphene sample. SEM images show the presence of ultra-thin layers with wrinkled paper-like structure (figure $3(a-b)$ ). TEM investigation (figure 3(c)) shows presence of graphene sheets displaying crystalline behaviour (see selected area diffraction (SAD) pattern in figure 3(d)). Arc nature of the reflections in SAD pattern indicates diffraction from multiple graphene sheets. 

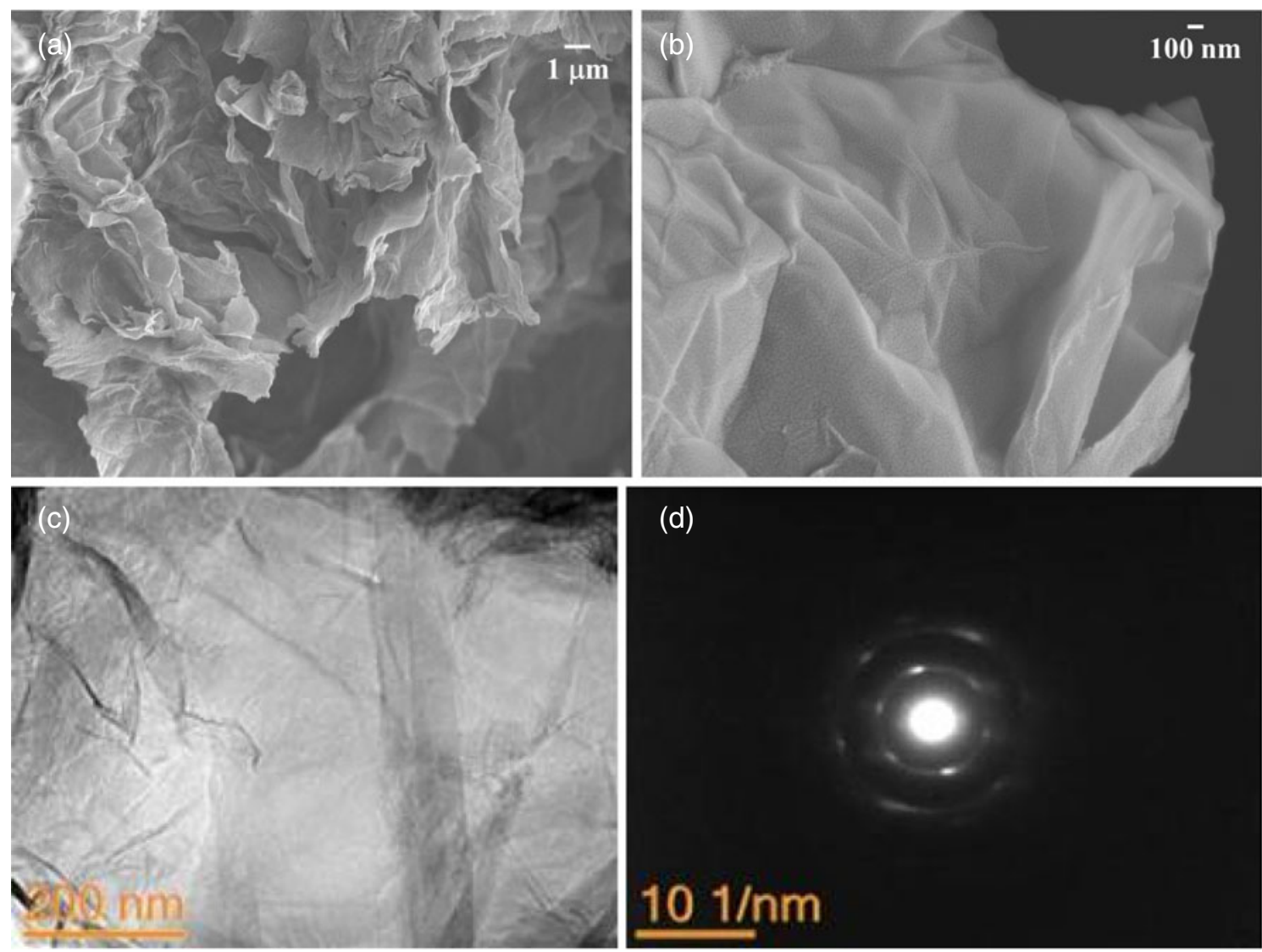

Figure 3. (a)-(b) SEM images of com-graphene surface, (c) TEM image showing individual graphene sheets in com-graphene and (d) electron diffraction confirming crystalline nature of sample.

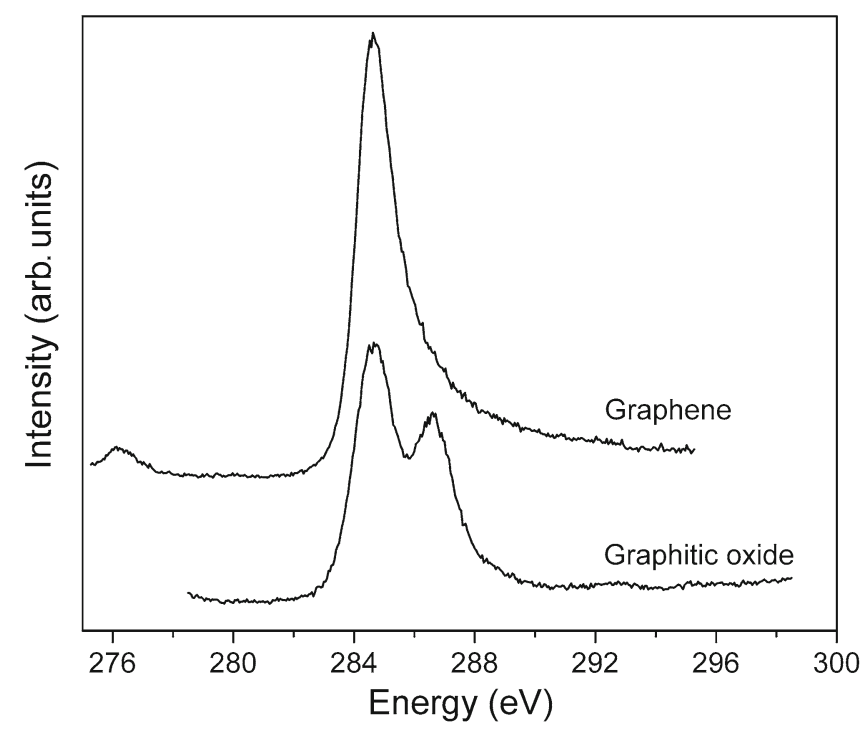

Figure 4. C1s XPS data of graphitic oxide and graphene.

$\mathrm{X}$-ray photoelectron spectroscopy (XPS) is performed on the as prepared com-graphene powders and $\mathrm{C} 1 s$ spectrum is shown in figure 4, along with that of graphitic oxide for reference. The intense peak with binding energy around $284.5 \mathrm{eV}$ is associated with $s p^{2}$-bonded carbon. Peaks of relatively lower intensities with binding energies between 286 and $289 \mathrm{eV}$ are attributed to $\mathrm{C}-\mathrm{O}$, carbonyl $(\mathrm{C}=\mathrm{O})$, carboxyl $(\mathrm{O}-\mathrm{C}=\mathrm{O})$, carbonate $(\mathrm{O}-\mathrm{C}(=\mathrm{O})-\mathrm{O}$ groups as well as $\beta-\mathrm{C}$ atoms attached to these functional groups (Staudenmaier 1898; Muszynski et al 2008; Wang et al 2009). XPS spectra of GO shows the non-oxygenated carbon peak $(284.6 \mathrm{eV})$ along with an intense peak corresponding to carbon atoms in different functional groups $(\mathrm{C}-\mathrm{O}$ bond: $286.5 \mathrm{eV} ; \mathrm{C}=\mathrm{O}$ bond: $288.2 \mathrm{eV}$ ), suggesting considerable degree of oxidation. The intensities of $\mathrm{C}-\mathrm{O}$ and $\mathrm{C}=\mathrm{O}$ peaks decreased significantly in com-graphene sample and the features appear as a shoulder. This indicates that combustion removes $\mathrm{C}-\mathrm{O}$, carbonyl and carboxylic groups to a larger extent, qualitatively $\mathrm{O} / \mathrm{C}$ ratio for $\mathrm{GO}$ is 0.32 which decreased to 0.06 for graphene. The small shoulder in comgraphene spectrum indicates the presence of small amount of functional groups. Graphene synthesized by chemical route is known to have residual functional groups, which can only be removed by further chemical/heat treatment (Gao et al 2009).

Ultracapacitor performance of com-graphene is studied using cyclic voltammetry (CV) and galvanostatic chargedischarge experiments. Figure 5 shows CV curves of comgraphene cell at different scanning rates. The shape of $\mathrm{CV}$ 


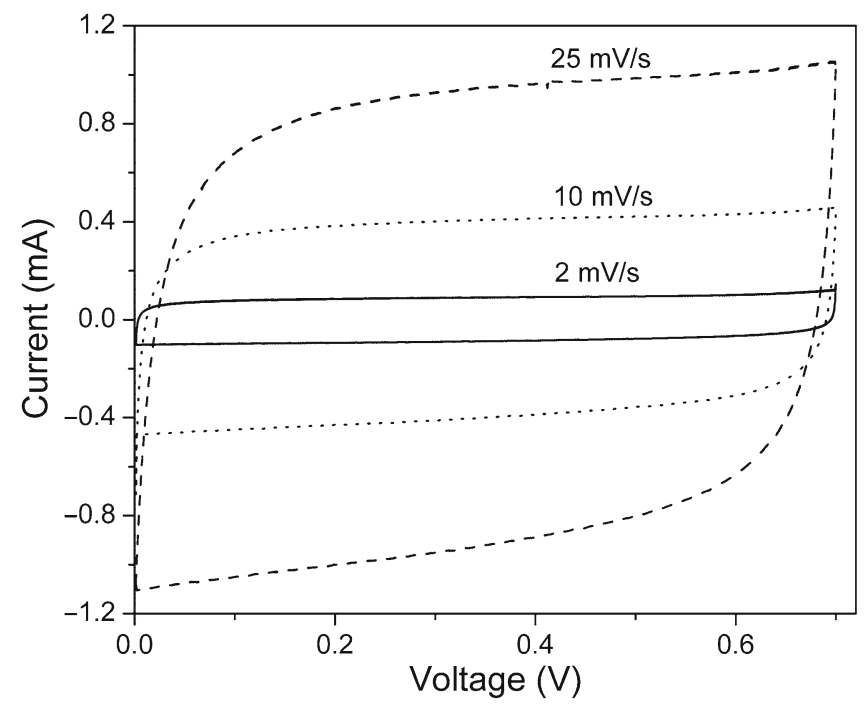

Figure 5. Cyclic voltammogram of com-graphene at different scanning rates.

is nearly rectangular in shape, confirming the capacitive behaviour of these cells. The presence of any significant amount of functional groups in graphene can lead to deviation from the rectangle shape. This is due to Faradaic redox processes occurring near the electrode surface. Du et al $(2010 \mathrm{a}, \mathrm{b})$ reported the pseudocapacitive behaviour for graphene synthesized by thermal treatment of $\mathrm{GO}$ at $250{ }^{\circ} \mathrm{C}$ (Du et al 2010b). In our work, although the synthesis temperature is same, no pseudocapacitance was observed suggesting that nearly all functional groups are removed for com-graphene sample. Specific capacitance was calculated from CV scans using (1)

$$
C(F / g)=\frac{2}{m}\left(\frac{I}{d V / d t}\right),
$$

where $m$ is the weight of one electrode (active weight of graphene), $I$ the charging current in ampere and $d V / d t$ the scanning rate in $V / \mathrm{s}$ (Conway 1999). The specific capacitance from $\mathrm{CV}$ measurement done at $10 \mathrm{mV} / \mathrm{s}$ is $58 \mathrm{~F} / \mathrm{g}$.

Figure 6 shows galvanostatic charge-discharge cycling of the cell at a current density of $50 \mathrm{~mA} / \mathrm{g}$. Specific capacitance was calculated from cycling data using (2)

$$
C(F / g)=\frac{2}{m}\left(\frac{I t}{V}\right),
$$

where $m$ is the weight of one electrode (weight of graphene), $I$ the current at which cycling is carried out, $V$ the voltage window of cycling and $t$ the discharge time in seconds (Conway 1999).

Specific capacitance obtained from charge-discharge cycling is around $80 \mathrm{~F} / \mathrm{g}$ at a current density of $25 \mathrm{~mA} / \mathrm{g}$. The variation of capacitance with respect to current density is studied by cycling the cell at different current densities and the results are shown in figure 6(b). Specific capacitance decreased from $\sim 80 \mathrm{~F} / \mathrm{g}$ at $25 \mathrm{~mA} / \mathrm{g}$ to $\sim 70 \mathrm{~F} / \mathrm{g}$
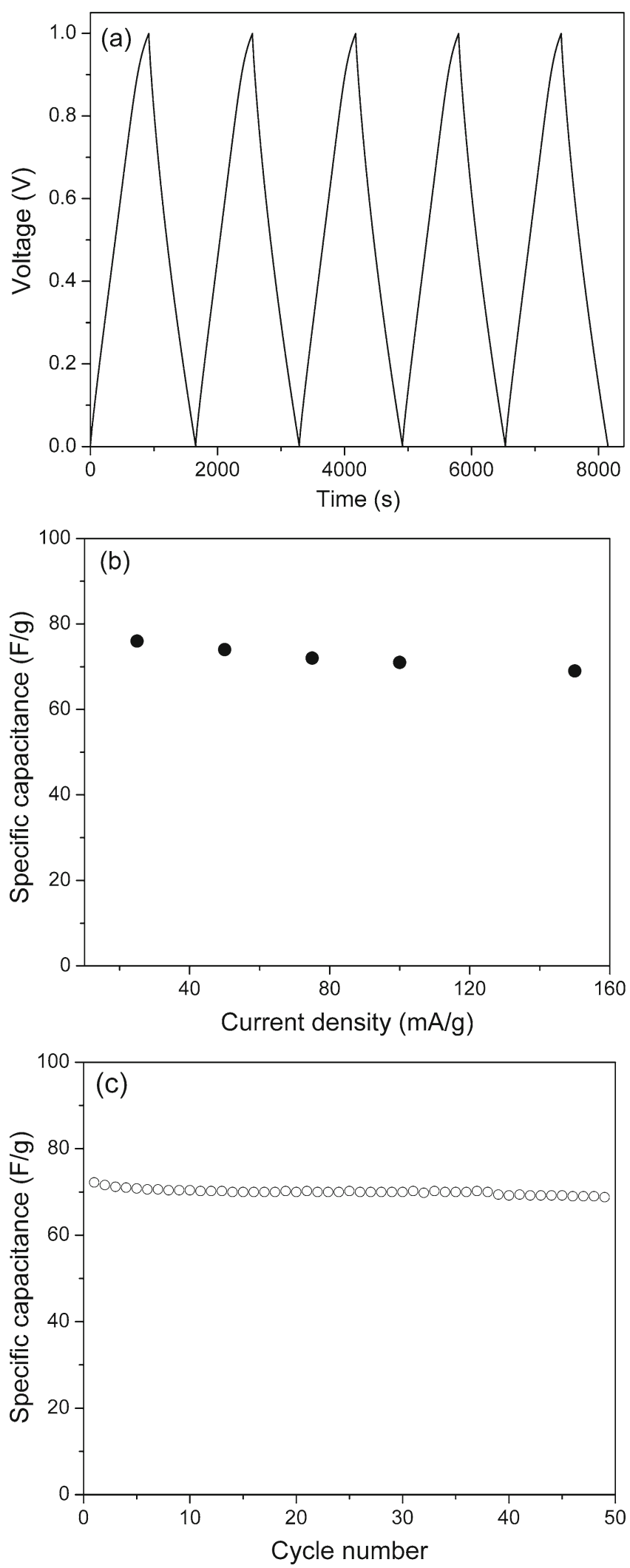

Figure 6. (a) Galvanostatic charge-discharge of a graphene cell at a current density of $25 \mathrm{~mA} / \mathrm{g}$, (b) variation of specific capacitance for graphene with respect to current density and (c) variation of specific capacitance with cycle number for graphene carried out at current density of $100 \mathrm{~mA} / \mathrm{g}$. 
at $150 \mathrm{~mA} / \mathrm{g}$. It indicates that the charge acceptance of graphene decreases with increase in current density. Figure 6(c) shows variation of specific capacitance with cycle number for com-graphene at a current density of $100 \mathrm{~mA} / \mathrm{g}$. The initial 50 cycles show good capacity retention with a specific capacitance of $\sim 70 \mathrm{~F} / \mathrm{g}$.

\section{Conclusions}

Graphene has been synthesized from graphitic oxide using a low temperature combustion method at $250{ }^{\circ} \mathrm{C}$. Specific capacitance of $\sim 80 \mathrm{~F} / \mathrm{g}$ is observed for com-graphene at a current density of $25 \mathrm{~mA} / \mathrm{g}$ and capacitance decreased with increase in current density. Further, optimization of synthesis is required to improve electrochemical performance.

\section{Acknowledgement}

Authors gratefully thank Mamatha Nagesh for her help in characterization.

\section{References}

Balandin A A et al 2008 Nano. Lett. 8902

Bhatkar V B, Omanwar S K and Moharil S V 2007 Opt. Mater. 29 1066

Biamino S and Badini C 2004 J. Eur. Ceram. Soc. 243021

Bolotin K I et al 2008 Solid State Commun. 146351

Brodie B C 1860 Ann. Chim. Phys. 59466

Conway B E 1999 Electrochemical supercapacitor: scientific fundamentals and technological applications (New York: Kluwer Academic/Plenum Publishers)
Du X, Guo P, Song H and Chen X 2010a Electrochim. Acta 55 4812

Du Q, Zheng M, Zhang L, Wang Y, Chen J, Xue L, Dai W, Ji G and Cao J 2010b Electrochim. Acta 553897

Gao W, Alemany L B, Ci L and Ajayan P M 2009 Nat. Chem. 1403

Geim A K and Novoselov K S 2007 Nat. Mater. 6183

Geim A K 2009 Graphene Status Prospects 3241530

He H, Riedl T, Lerf A and Klinowski J 1996 J. Phys. Chem. 100 19954

Hummers W S and Offeman R E 1958 J. Am. Chem. Soc. 801339

Lee C, Wei X, Kysar J W and Hone J 2008 Science 321385

Lerf A, He H, Forster M and Klinowski J 1998 J. Phys. Chem. B102 4477

Muszynski R, Seger B and Kamat P V 2008 J. Phys. Chem. C112 5263

Novoselov K S, Giem A K, Morozov S V, Jiang D, Zhang Y, Dubonos S V, Grigorieva I V and Firsov A A 2004 Science 306 666

Park S J and Ruoff R S 2009 Nature Nanotech. 4217

Singh V, Joung D, Zhai L, Das S, Khondaker S I and Seal S 2011 Prog. Mater. Sci. 561178

Somani P R, Somani S P and Umeno M 2006 Chem. Phys. Lett. 43056

Staudenmaier L 1898 Ber. Deut. Chem. Ges. 311481

Stroller M D, Park S, Zhu Y, An J and Ruoff R S 2008 Nano. Lett. 83498

Wakeland S, Martinez R, Grey J K and Luhrs C 2010 Carbon 483463

Wang G, Yang J, Park J, Gou X, Wang B, Liu H and Yao J 2008 J. Phys. Chem. C112 8192

Wang Y, Shi Z, Huang Y, Ma Y, Wang C, Chen M and Chen Y 2009 J. Phys. Chem. C113 13103

Zhu Y, Murali S, Stoller M D, Velamakanni A, Piner R D and Ruoff R S 2010a Carbon 482118

Zhu Y, Stoller M D, Cai W, Velamakanni A, Piner R D, Chen D and Ruoff R S 2010b Am. Chem. Soc. Nano. 41227 